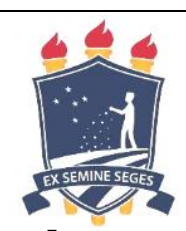

\title{
Avaliação do efeito antimicrobiano in vitro dos extratos etanólicos de Plectranthus neochilus e Cnidoscolus quercifolius
}

\author{
[Evaluation of the in vitro antimicrobial effect of ethanolic extracts of Plectranthus neochilus and \\ Cnidoscolus quercifolius]
}

\section{"Artigo Científico/Scientific Article"}

\author{
Evilda Rodrigues de Lima ${ }^{1 *}$, Bárbara Nogueira da Silva ${ }^{1}$, Rhaysa Allayde Silva Oliveira ${ }^{1}$, Laís \\ Albuquerque van der Linden ${ }^{1}$, Vanessa Carla Lima da Silva ${ }^{2}$, Michelle Suassuna de Azevedo \\ Rêgo $^{3}$, Melânia Loureiro Marinho ${ }^{4}$
}

\begin{abstract}
${ }^{1}$ Departamento de Medicina Veterinária, Universidade Federal Rural de Pernambuco, Recife-PE, Brasil. ${ }^{2}$ Departamento de Medicina Veterinária, Centro Universitário Unifavip/Wyden, Caruaru-PE, Brasil. ${ }^{3}$ Hospital Veterinário de Recife, Recife-PE, Brasil.

${ }^{4}$ Departamento de Medicina Veterinária, Universidade Federal de Campina Grande, Patos-PB, Brasil.

*Autor para correspondência/Corresponding author: E-mail: evilda17@ @otmail.com
\end{abstract}

\section{Resumo}

Avaliou-se o efeito antimicrobiano in vitro dos extratos etanólicos de Plectranthus neochilus e Cnidoscolus quercifolius de forma isolada e associadas. $\mathrm{Na} 1^{\mathrm{a}}$ etapa, utilizaram-se os extratos em concentrações $1 \%, 2,5 \%$, $5 \%$ e $10 \%$. Na $2^{\text {a }}$ etapa, utilizaram-se apenas extratos brutos. Para o teste de sensibilidade dos extratos, utilizaram-se cepas padrão Staphylococcus aureus ATCC 25923, Escherichia coli ATCC 25922, Pseudomonas aeruginosa ATCC 27853. Nas duas etapas, realizaram-se os mesmos testes de sensibilidade. As placas foram semeadas e lidas após 24 horas de incubação em estufa a $37^{\circ} \mathrm{C}$. De acordo com os resultados, conclui-se que não houve atividade bacteriana dos extratos etanólicos estudados isolados, bem como associados diante das cepas padrão de Staphylococcus aureus, Escherichia coli e Pseudomonas aeruginosa nas diferentes metodologias aplicadas quando comparadas com o antibiótico padrão (amicacina).

Palavras-chave: cepas ATCC; Cnidoscolus quercifolius; fitoterapia; Plectranthus neochilus.

\begin{abstract}
The in vitro antimicrobial effects of the ethanolic extracts of Plectranthus neochilus and Cnidoscolus quercifolius in their isolated and combined forms were evaluated. In the first phase, the extracts were used in a concentration of $1 \%, 2.5 \%, 5 \%$, and $10 \%$. In the second phase, only raw extracts were used. For the sensitivity test of the extracts, standard strains of Staphylococcus aureus ATCC 25923, Escherichia coli ATCC 25922, and Pseudomonas aeruginosa ATCC 27853 were used. In both phases, the same sensitivity tests were performed. The plates were seeded and read after a 24 -hour incubation period in a laboratory oven at $37^{\circ} \mathrm{C}$. According to the results, it is concluded that the ethanolic extracts studied, either separately or combined, showed no antibacterial activity against standard strains of Staphylococcus aureus, Escherichia coli, and Pseudomonas aeruginosa under the different methods used when compared to the standard antibiotic (amikacin).
\end{abstract}

Keywords: ATCC strains; Cnidoscolus quercifolius; phytotherapy; Plectranthus neochilus.

\section{Introdução}

A utilização de plantas com fins medicinais para tratamento, cura e prevenção de doenças é uma das mais antigas formas de prática medicinal da humanidade (Veiga Junior et al., 2005), com documentação muito bem estudada, que serve para ilustrar como as plantas, ao longo das eras, desempenharam um papel proeminente na manutenção da saúde (Eldem e Dunford, 2001). 
No Brasil, a utilização de plantas no tratamento de doenças apresenta fundamentalmente influências da cultura indígena, africana e, naturalmente, europeia. Essas influências constituíram a base da medicina popular que vem sendo retomada pela medicina natural, apresentando caráter científico e integrando-as em um conjunto de princípios que visam não apenas curar algumas doenças, mas restituir o homem à vida natural. Tal conjunto de conhecimentos sobre o uso de plantas é uma prática generalizada na medicina popular, utilizada nas mais variadas doenças, tanto na medicina humana como na medicina veterinária (Albuquerque, 1989; Martins et al., 1995).

Plectranthus neochilus (Lamiaceae) é uma planta herbácea, conhecida, vulgarmente, como boldo pequeno, boldo rasteiro ou boldo gambá. Tem folhas pequenas, quase triangulares, dispostas compactamente, levemente amargas e de odor forte, principalmente quando está florida (Lorenzi e Matos, 2008). Os usos populares dessas espécies incluem tratamento de dor de cabeça, feridas, queimaduras, dermatite, alergias e picadas de inseto e de escorpião, e como agente antisséptico. As plantas do gênero são também uma importante fonte de novos compostos bioativos e potenciais medicamentos. Várias espécies de Plectranthus são cultivadas também como tubérculos comestíveis, condimentos e plantas ornamentais. As plantas são ainda importantes fontes de óleos essenciais (Ascensão et al., 1999), utilizados amplamente em preparações farmacêuticas, em perfumaria e cosméticos (Ascensão et al., 1998).

Cnidoscolus quercifolius Pohl é popularmente conhecida como favela ou faveleira, pertencente ao gênero Cnidoscolus, família Euphorbiaceae. Encontra-se nos estados do Nordeste brasileiro (Duque, 2004). É popularmente utilizada para recuperar áreas degradadas, para a alimentação animal e humana, para a medicina popular, para serrarias como fonte de energia e para diversos outros usos (Pordeus Neto et al., 2009). Em relação ao uso na medicina popular, usa-se para combater a inflamação (Lorenzi e Matos, 2008).

Diante dessa importância, as espécies Plectranthus neochilus (Boldo gambá) e Cnidoscolus quercifolius (Favela) têm sido estudadas como possíveis alternativas no tratamento de inflamação e infecção na pele, de forma que esta pesquisa teve por objetivo avaliar o efeito antimicrobiano dos extratos etanólicos dessas plantas, diante das cepas padrão de Staphylococcus aureus, Escherichia coli e Pseudomonas aeruginosa in vitro.

\section{Material e Métodos}

As folhas de Plectranthus neochilus Schlechter (Lamiaceae) e a entrecasca de Cnidoscolus quercifolius Pohl (Euphorbiaceae) foram coletadas, no período da manhã, de espécimes localizadas na mesorregião do Sertão Paraibano, município de Patos, Paraíba ( $7^{\circ} 01^{\prime} 28^{\prime \prime}$ Sul, 37 $16^{\prime} 48^{\prime \prime}$ Oeste). O Departamento de Engenharia Florestal da Universidade Federal Rural de Pernambuco (UFRPE) identificou amostras desse material. Esse material coletado refere-se à obtenção dos extratos para a extração 1 . Para a extração 2, a Universidade Federal de Campina Grande (UFCG), campus de Patos cedeu os extratos prontos. Os extratos foram obtidos de duas formas distintas, com o intuito de testar se havia diferença de resultados quanto à origem dos extratos.

A obtenção dos extratos etanólicos na $1^{\text {a }}$ etapa foi realizada no Laboratório de Produtos Naturais Bioativos no Departamento de Química LPNBio (UFRPE) por meio da desidratação de 500 $\mathrm{g}$ de folhas de Plectranthus neochilus e $500 \mathrm{~g}$ de entrecasca de Cnidoscolus quercifolius.

Esses materiais foram desidratados em estufa de circulação de ar a $40^{\circ} \mathrm{C}$ por 24 horas, pesados e triturados em liquidificador. O material resultante de cada planta foi colocado em balão de fundo chato adicionado a $1 \mathrm{~L}$ de uma solução (EtOH: ÁGUA 1:1), deixando em repouso por uma semana a temperatura ambiente; em seguida, o material foi filtrado a vácuo.

Os líquidos obtidos foram colocados em balão de fundo redondo e levados ao rotoevaporador a temperatura de aproximadamente $40^{\circ} \mathrm{C}$ a $60^{\circ} \mathrm{C}$ e pressão de, aproximadamente, 650 $\mathrm{mmHg}$. Os extratos foram acondicionados em refrigerador até a realização dos experimentos. As extrações foram realizadas de acordo com as especificações do Laboratório de Produtos Naturais Bioativos (LPNBio) da UFRPE como descrito por Pontes et al. (2007).

Nessa $1^{\text {a }}$ etapa, foram utilizados os extratos brutos nas concentrações: $1 \%, 2,5 \%, 5 \%$ e $10 \%$. Em todas as concentrações, foi feito o mesmo protocolo de diluição, exceto pela quantidade de cada extrato. Para obter concentração a $1 \%$, foi colocado em microtubo do tipo eppendorf $0,010 \mathrm{~g}$ de cada extrato bruto (Boldo gambá e Favela) e pesados em balança analítica. Nas demais concentrações $(2,5 \%, 5 \%$ e $10 \%)$, foram utilizadas respectivamente $0,025 \mathrm{~g}, 0,050 \mathrm{~g} \mathrm{e} 0,10 \mathrm{~g}$.

Foram acrescentados $10 \mu \mathrm{L}$ do solvente Dimetilsulfóxido (DMSO) a cada tubo distinto. Essa mistura foi colocada no termociclador por 3 minutos. Depois desse tempo, foi adicionado 0,1 $\mathrm{mL}$ de água destilada e mais 5 minutos no 
termociclador. Ao fim dos 5 minutos, foi acrescentado mais $0,9 \mathrm{~mL}$ de água destilada por mais 2 minutos. Foram utilizados os mesmos diluentes em todas as concentrações: $10 \mu \mathrm{L}$ de DMSO e $1 \mathrm{~mL}$ de água destilada.

A obtenção dos extratos etanólicos na $2^{\mathrm{a}}$ etapa foi realizada no Laboratório de Fitoterapia do Centro de Saúde e Tecnologia Rural da Universidade Federal de Campina Grande (UFCG), campus de Patos. Foram utilizadas folhas de Boldo gambá e a entrecasca da Favela, sendo 200 g de cada planta para um litro de solução hidroalcoólica $(50 \%$ de água $+50 \%$ de álcool de cereais), e mantidas em repouso por 72 horas. Esses extratos brutos foram cedidos pela UFCG, campus de Patos, e não foram diluídos em diferentes concentrações.

Para manutenção das cepas, o meio de cultura utilizado foi Ágar Mueller-Hinton (AMH da marca Himedia ${ }^{\circledR}$ ). A preparação do meio foi de acordo com as recomendações do fabricante. Foram diluídos $38 \mathrm{~g}$ do Ágar Mueller-Hinton em $1.000 \mathrm{~mL}$ de água destilada com aquecimento constante em micro-ondas. Depois da dissolução, o material foi autoclavado a $121^{\circ} \mathrm{C}$ por 15 minutos e distribuído em placas de Petri estéreis sem divisão (90x15mm). Cada placa continha $15 \mathrm{~mL}$ do material, e foram armazenadas após resfriamento, invertidas sob refrigeração.

Foram utilizadas cepas padrão American Type Culture Collection (ATCC) adquiridas do Laboratório Laborclin®. Os microrganismos testes foram Staphylococcus aureus ATCC 25923, Escherichia coli ATCC 25922 e Pseudomonas aeruginosa ATCC 27853.

A ativação das cepas liofilizadas foi realizada de acordo com a técnica estabelecida pelo fabricante. As cepas ficaram em temperatura ambiente; posteriormente, foi aberto cada frasco de cepa individualmente, acrescentando $3 \mathrm{~mL}$ de Caldo Triptona de Soja - TSB (Himedia ${ }^{\circledR}$ ). Depois de suave homogeneização, e aguardados 3 minutos, o material foi incubado em estufa bacteriológica a $37^{\circ} \mathrm{C}$ por 4 horas com a finalidade de ativar as cepas. Depois de ativado, o material foi inoculado em meio não seletivo (Ágar Sangue) e incubado em estufa bacteriológica a $37^{\circ} \mathrm{C}$ por 24 horas.

$\mathrm{O}$ teste de sensibilidade dos extratos foi realizado no Laboratório de Inspeção de Carne e Leite do Departamento de Medicina Veterinária da UFRPE. A avaliação da atividade antimicrobiana dos extratos etanólicos diante das cepas padrão in vitro foi por meio do Método de Disco Difusão (Bauer et al., 1966) adaptado, recomendado pelo Clinical and Laboratory Standards Institute (CLSI, 2003). Do inóculo microbiano incubado em Ágar Sangue, foram retiradas algumas colônias (cultivo jovem de 24 horas de incubação) e suspensas em solução salina estéril $(\mathrm{NaCl} 0,85 \%)$ até ajuste da turvação equivalente à escala 0,5 de McFarland, obtendo-se uma concentração bacteriana final em torno de $1,5 \times 10^{6} \mathrm{cel} / \mathrm{mL}$.

Posteriormente, com swab esteril, foram semeadas, com cada cepa, as placas com meio de cultura Ágar Mueller-Hinton. Para cada tipo de cepa padrão (Staphylococcus aureus, Escherichia coli e Pseudomonas aeruginosa), foram semeadas duas placas de Petri, repetindo-se esse procedimento no dia seguinte. Em ambas as etapas, foram utilizados discos de papel de filtro estéreis (Laborclin $\left.{ }^{\circledR}\right)$ com $6 \mathrm{~mm}$ de diâmetro e os discos para colocação dos extratos e dos controles positivo e negativo. Na $1^{\mathrm{a}}$ etapa, previamente, os discos foram impregnados com $20 \mu \mathrm{L}$ dos extratos brutos (Boldo gambá: 1\%, 2,5\%, 5\%, 10\%; Favela: $1 \%, 2,5 \%, 5 \%, 10 \%$ ), e $20 \mu \mathrm{L}$ de ambos os extratos $-10 \mu \mathrm{L}$ para cada extrato a $1 \%, 2,5 \%, 5 \%, 10 \%$.

$\mathrm{Na} 2^{\mathrm{a}}$ etapa, os discos estéreis foram impregnados com $20 \mu \mathrm{L}$ do extrato bruto de Boldo gambá, $20 \mu \mathrm{L}$ do extrato bruto de Favela e $20 \mu \mathrm{L}$ ( $10 \mu \mathrm{L}$ de cada extrato) de ambos os extratos. Todo o procedimento, nas duas etapas, foi realizado na capela de fluxo laminar, com material estéril.

Para controle negativo, foram utilizados discos estéreis impregnados com DMSO e água destilada estéril; para controle positivo, disco de amicacina $(10 \mu \mathrm{g}) \quad$ Laborclin $®$. Os discos impregnados com as amostras dos extratos foram mantidos em estufa à temperatura de $37^{\circ} \mathrm{C}$ por 10 minutos para uma breve secagem; sendo, em seguida, distribuídos equidistantes com o auxílio de uma pinça estéril sobre a superfície do meio de cultura previamente semeado com inóculo bacteriano.

Em todas as placas de Petri, estabeleceu-se a seguinte ordem: 1. extrato de Boldo gambá; 2. extrato de Favela; 3. extratos de Boldo gambá e Favela; 4. controle positivo de amicacina; 5. controle negativo de DMSO e água destilada. As placas de ambas as etapas foram incubadas invertidas a $37^{\circ} \mathrm{C}$ por 24 horas. Após esse período, o diâmetro da zona de inibição foi mensurado com uma régua para expressão dos resultados em média (em milímetros) dos diâmetros de inibição com halos inibitórios superiores a $12 \mathrm{~mm}$ (Bezerra et al., 2009).

\section{Resultados e Discussão}

Os resultados dos extratos etanólicos brutos $(1 \%, 2,5 \%, 5 \%, 10 \%)$ ativos das folhas de Plectranthus neochilus (Boldo gambá) e entrecascas de Cnidoscolus quercifolius (Favela) diante das cepas ATCC na $1^{\text {a }}$ etapa da pesquisa. De acordo com os resultados, constatou-se que não 
houve inibição bacteriana em nenhuma das concentrações testadas, como também nos extratos isolados e associados.

Os resultados dos extratos etanólicos brutos ativos das folhas de Plectranthus neochilus (Boldo gambá) e entrecascas de Cnidoscolus quercifolius (Favela) diante das cepas ATCC na $2^{\mathrm{a}}$ etapa da pesquisa. De acordo com os resultados, constatouse que não houve inibição bacteriana nos extratos isolados e associados.

A Tabela 1 apresenta a média das quatro repetições do controle positivo com amicacina diante das cepas ATCC na $1^{\mathrm{a}}$ e na $2^{\mathrm{a}}$ etapa da pesquisa. Quando em comparação com os demais resultados, nota-se a ausência de efeito antimicrobiano dos extratos, e apenas do controle positivo, como esperado.

Esses diferentes resultados podem estar relacionados com o fato de que na $1^{\mathrm{a}}$ etapa houve 16 repetições (duas duplicatas para cada concentração) e na $2^{\mathrm{a}}$ etapa, quatro repetições. Os valores encontrados estão, na maioria, dentro dos parâmetros de referência (S. aureus $20-26 \mu \mathrm{L} ; E$. coli 19-26 $\mu \mathrm{L} ;$ P. aeruginosa 18-26 $\mu \mathrm{L}$ ) do Laboratório Laborclin ${ }^{\circledR}$. Em ambas as etapas, não houve atividade dos extratos brutos diante das cepas testadas.

Tabela 1. Média dos extratos etanólicos brutos ativos das folhas de Plectranthus neochilus (Boldo gambá) e entrecascas de Cnidoscolus quercifolius (Favela), nas concentrações de 1\%, 2,5\%,5\%, 5\% e 10\%, com amicacina (controle positivo) diante das cepas ATCC na $1^{\mathrm{a}}$ e $2^{\mathrm{a}}$ etapa da pesquisa.

\begin{tabular}{ccccc}
\hline Etapa & Controle positivo & \multicolumn{3}{c}{ Atividade diante dos micro-organismos } \\
\hline & & Staphylococcus aureus & Escherichia coli & Pseudomonas aeruginosa \\
& & ATCC 25923 & ATCC 25922 & ATCC 27853 \\
\hline $1^{\text {a }}$ Etapa & Amicacina $\AA$ & $27,68 \mu \mathrm{L}$ & $26,43 \mu \mathrm{L}$ & $32,5 \mu \mathrm{L}$ \\
$2^{\text {a }}$ Etapa & Amicacina $\AA$ & $22,75 \mu \mathrm{L}$ & $27 \mu \mathrm{L}$ & $28,5 \mu \mathrm{L}$ \\
\hline
\end{tabular}

$1^{a}$ etapa: os discos estéreis foram impregnados previamente com $20 \mu \mathrm{L}$ dos extratos brutos (Plectranthus neochilus: $1 \%, 2,5 \%, 5 \%$, $10 \%$; Cnidoscolus quercifolius: $1 \%, 2,5 \%, 5 \%, 10 \%$ ), e $20 \mu \mathrm{L}$ de ambos os extratos $-10 \mu \mathrm{L}$ para cada extrato a $1 \%, 2,5 \%, 5 \%, 10 \%$. $2^{\text {a }}$ etapa: os discos estéreis foram impregnados com $20 \mu \mathrm{L}$ do extrato bruto de Plectranthus neochilus, $20 \mu \mathrm{L}$ do extrato bruto de Cnidoscolus quercifolius e $20 \mu \mathrm{L}$ de ambos os extratos (10 $\mu \mathrm{L}$ de cada extrato).

Rêgo et al. (2018) utilizaram o gel fitoterápico da associação da Plectranthus neochilus (Boldo gambá) e Cnidoscolus quercifolius (Favela) nas concentrações de 2,5\%, $5 \%$ e $10 \%$; quando comparadas com o controle positivo gel fitoterápico já existente no mercado (10 mL de tintura de Calendula officinalis L.; 10 $\mathrm{mL}$ de tintura de Stryphnodendron barbatiman Mart.; $5 \mathrm{~mL}$ de tintura de Symphyntum officinalis L.; $5 \mathrm{~mL}$ de tintura de Aloe vera; $3 \mathrm{~mL}$ de tintura de Matricaria chamomilla L.; $5 \mathrm{~mL}$ de tintura de Echinacea angustifolia DC.; $8 \mathrm{~mL}$ de tintura de própolis, $100 \mathrm{~g}$ do gel carbopol), não resultou em melhora significativa na redução do tempo para o processo de cicatrização das feridas cutâneas cirúrgicas em ratos Wistar. Contudo, entre as três formulações, a de $2,5 \%$ foi aquela que apresentou aumento na proliferação de fibroblastos e colagenização mais intensa no $14^{\circ}$ dia de tratamento. Nesse experimento, também se avaliou a atividade antimicrobiana dos extratos diante das cepas de Staphylococus aureus, Staphylococus epidermidis e Escherichia coli por disco difusão, tendo como resultado a ausência de inibição antimicrobiana. Dados que corroboram os resultados do atual experimento.

Pereira et al. (2015) obtiveram os extratos aquoso, acetônico e metanólico de $P$. neochilus utilizando inúmeros métodos de extração (infusão, decocção, maceração, extração assistida por microondas e por ultrassom e com fluidos no estado supercrítico). Foram utilizados para controle positivo (vancomicina, anfotericina $\mathrm{B} e$ norfloxacina) e controle negativo (DMSO). Todos os extratos foram testados quanto à atividade antimicrobiana em face das bactérias Grampositivo (Enterococcus faecalis, Staphylococcus aureus, Staphylococcus epidermidis Bacillus subtilis e Mycobacterium smegmatis) e Gramnegativo (Pseudomonas aeruginosa, Klebsiella pneumoniae e Escherichia coli). $\mathrm{O}$ extrato acetônico de $P$. neochilus obtido pela técnica de ultrassom demonstrou atividade contra as cinco bactérias Gram-positivo testadas (5-24 mm de zona de inibição no teste de difusão), diferentemente dos resultados encontrados no presente estudo.

Resultados similares aos encontrados nesta pesquisa foram verificados por Eller et al. (2015); como controle negativo foram utilizados discos estéreis impregnados com álcool etílico a 70\%, e no controle positivo, foi utilizado o disco de amicacina $(10 \mu \mathrm{g})$ da Cecon®. Foi observada ausência de atividade dos extratos brutos de favela, fedegoso e quixaba diante das cepas padrão de Staphylococcus aureus ATCC 25923, Escherichia coli ATCC 25922 e Pseudomonas aeruginosa 
ATCC 27853, testados pelo método de difusão em disco.

Nunes et al. (2016) avaliaram a atividade antimicrobiana do extrato etanólico da casca da espécie Cnidoscolus quercifolius pelo método de difusão em ágar por meio de poço. Como controle positivo, foram utilizados $20 \mu \mathrm{L} / \mathrm{mg}$ de ciprofloxacina e gentamicina e $20 \mu \mathrm{L}$ de DMSO $0,1 \%$, usado como controle negativo. Os resultados demonstraram que não houve atividade antimicrobiana diante das espécies bacterianas $E$. faecales, $S$. pneumoniae e $S$. aureus.

$\begin{array}{clr}\text { Pesquisas } & \begin{array}{l}\text { realizadas com } \\ \text { quercifolius }\end{array} & \begin{array}{r}\text { Cnidoscolus } \\ \text { comprovaram }\end{array} \\ \text { atividades }\end{array}$ antinociceptiva e anti-inflamatória em camundongos. Ferreira et al. (2013), utilizando a pomada fitoterápica contendo extratos de Plectranthus neochilus e Cnidoscolus quercifolius em gatas submetidas a ovariossalpingohisterectomia, constataram o efeito anti-inflamatório, diminuição da dor e melhor cicatrização, levando em consideração os parâmetros avaliados nesse experimento. Embora nenhum desses efeitos tenha sido avaliado no presente experimento, salienta-se a importância da aplicabilidade desses extratos em outras situações.

Ribeiro et al. (2017) avaliou o efeito antioxidante e antibacteriano do óleo da semente de faveleira obtido por prensagem a frio e verificaram que tem potencial antioxidante. No entanto, as amostras não apresentaram atividade antibacteriana em suas frações metanólicas e apolar de acordo com National Committee for Clinical Laboratory Santards. As culturas foram cultivadas em ágar Muller-Hinton por $24 \mathrm{~h}$ a $35^{\circ} \mathrm{C}$, seguido de suspensão em solução salina estéril $(0,5$ da escala de McFarland, $10^{8} \mathrm{UFC} / \mathrm{mL}$ ). As suspensões foram espalhadas na superfície das placas de ágar MullerHinton e discos de $6 \mathrm{~mm}$ de diâmetro contendo 20 $\mu \mathrm{L}$ de extratos estéreis. Foi utilizado para controle positivo amoxilina e penicilina e controle negativo solventes usados na extração. Nove estirpes bacterianas foram usadas, quatro bactérias (Grampositivo) (Staphylococcus aureus ATCC 29213, Listeria monocytogenes ATCC 15313, Bacillus cereus ATCC 11778 e Enterococcus faecalis ATCC 29212) e cinco bactérias (Gram-negativo) (Pseudomonas aeruginosa ATCC 27853, Enterobacter cloacae ATCC13047, Escherichia coli ATCC 25922, Salmonella typhimurium ATCC 14028, Enterobacter aerogenes ATCC 13048), corroborando o resultado desta pesquisa.

\section{Conclusão}

De acordo com os resultados obtidos, podese concluir que não houve atividade antimicrobiana in vitro dos extratos etanólicos de Plectranthus neochilus (Boldo gambá) e Cnidoscolus quercifolius (Favela) diante das cepas padrão de Staphylococcus aureus ATCC 25923, Escherichia coli ATCC 25922 e Pseudomonas aeruginosa ATCC 27853 nas diferentes metodologias aplicadas. Contudo, este estudo ressalta a importância de pesquisas de agentes antimicrobianos naturais, contribuindo para o uso racional das plantas como terapêutica auxiliar nas infecções.

\section{Conflito de interesse}

Os autores declaram não existir conflito de interesse.

\section{Comitê de Ética}

O protocolo experimental foi aprovado pela Comissão de Ética no Uso de Animais (CEUA/UFPE), n. ${ }^{\circ}$ 23076.011939/2014-25 e cadastrado no Sistema Nacional de Gestão do Patrimônio Genético e do Conhecimento Tradicional Associado (SISGEN) com n. ${ }^{\circ}$ A7523E1.

\section{Agradecimentos}

À Coordenação de Aperfeiçoamento de Pessoal de Nível Superior (Capes), a bolsa cedida em confiança no nosso trabalho.

\section{Referências}

Albuquerque, J.M. Plantas medicinais de uso popular. Brasília: Ministério da Educação, 1989, 96p.

Ascensão, L.; Figueiredo, A.C.; Barroso, J.G.; Pedro, L.G.; Schripsema, J.; Deans, S.G. Plectranthus madagascariensis: morphology of the glandular trichomes, essential oil composition, and its biological activity. Journal of Plant Sciences, 159(1): 31-38, 1998.

Ascensão, L.; Mota, L.; Castro, M. Glandular trichomes on the leaves and flowers of Plectranthus ornatus: morphology, distribution and histochemistry. Annals of Botany, 84(4): 437-447, 1999.

Bauer, A.W.; Kirby, W.M.M.; Sherris, J.C.; Turck, M. Antibiotic susceptibility testing by a standardized single disc method. The American Journal of Clinical Pathology, 45(4), 1966.

Bezerra, D.A.C.; Pereira, A. V.; Lôbo, K.M.S.; Rodrigues, O.G.; Athayde, A.C.R.; Mota, R.A. et al. Atividade biológica da jurema-preta (Mimosa tenuiflora (Wild) Por.) sobre Staphylococcus aureus isolado de casos de mastite bovina. Revista Brasileira de Farmacognosia, 19(4): 814-817, 2009. 
CLSI. Clinical Laboratory Standards Institute. Padronização dos testes de sensibilidade a antimicrobianos por disco-difusão: norma aprovada. $8^{\text {a }}$ ed. M2-8, 23(1), 2003.

Duque, J.G. Perspectivas nordestinas. $2^{\mathrm{a}}$ ed. Fortaleza: Banco do Brasil, 2004. 424p.

Eldem, S.; Dunford, A. Fitoterapia: atenção primária à saúde. Rio de Janeiro: Editora Brasileira, 2001. p. 7-13.

Eller, S.C.W. S.; Feitosa, V.A.; Arruda, T.A.; Antunes, R.M.P; Catão, R.M.R. Avaliação antimicrobiana de extratos vegetais e possível interação farmacológica in vitro. Revista de Ciências Farmacêuticas Básica e Aplicada, 36(1):131-136, 2015.

Ferreira, G.S.M.; Silva, N.S.; Nóbrega Neto, P.I.; Assis, M.B.; Alves, A.S.; Alves, A.P. Avaliação do efeito cicatrizante e analgésico da pomada fitoterápica contendo extratos de Plectranthus neochilus e Cnidoscolus phyllacanthus em gatas submetidas a ovariossalpingohisterectomia. Revista Verde de Agroecologia e Desenvolvimento Sustentável, 7(5): 34-40, 2013.

Lorenzi, H.; Matos, F.J.A. Plantas medicinais no Brasil: nativas e exóticas cultivadas. São Paulo: Instituto Plantarum de Estudos da Flora, 2008. 576p.

Martins, E.R.; Castro, D.M.; Castellani, D.C.; Dias, J.E. Plantas medicinais. Viçosa: Universidade Federal de Viçosa, 1995. 220p.

Nunes, F.R.S.; Dias, H.M.C.; Cavalcante, G. M. Investigação das atividades antioxidante e antimicrobiana de duas espécies arbóreas ocorrentes no bioma caatinga. Estação Científica (Unifap), 6(1): 81-90, 2016.
Pereira, M.; Matias, D.; Pereira, F.; Reis, C.P.; Simões, M.F.; Rijo, P. Pesquisa da actividade antimicrobiana de extratos de Plectranthus madagascariensis e $P$. neochilus. Biopharmaceutical Sciences, 12(1): 127-138, 2015.

Pontes, W.J.T.; Oliveira, J.C.S.; Câmara, C. A. G.; Lopes, A. C. H. R.; Gondim Júnior, M. G. C.; Oliveira, J.V.; Schwartz, M.O. Composition and acaricidal activity of the resin's essential oil of protium bahianum daly against two spotted spider mite (Tetranychus urticae). The Journal of Essential Oil Research, 19(4): 379-383, 2007.

Pordeus Neto, J.; Rodrigues, O.G.; Lima, E.Q.; Marinho, M.G.V.; Dantas, J.P. Avaliação da ação clastogênica do óleo de cnidoscolus phyllacanthus (mart.) pax. et $k$. hoffm em células medulares. Revista de Biologia e Farmácia, 3(1): 6-22, 2009.

Rêgo, M.S.A.; Silva, V.C.L.; Maia, C.S.; Teixeira, M.N.; Marinho, M.L. Avaliação da segurança do extrato hidroalcoólico de partes aéreas de Plectranthus neochilus schlechter, lamiaceae e entrecascas de Cnidoscolus quercifolius pohl, eupharbiaceae em roedores. Medicina Veterinária, 12(2): 82-92, 2018.

Ribeiro, P.P.C.; Lima e Silva, D.M.; Assis, C.F.; Correira, R.T.P.; Damasceno, K.S.F.S.C. Bioactive properties of faveleira (Cnidoscolus quercifolius) seeds, oil and press cake obtained during oilseed processing. PLoS One, 12(12): e0189563, 2017.

Veiga Junior, V.F.; Pinto, A.C.; Maciel, M.A.M. Plantas medicinais: cura segura? Química Nova, 28(3): 519-528, 2005. 